\title{
Pendampingan Budidaya dan Pengolahan Nutrasetikal Daun Bangun-bangun untuk Ibu Rumah Tangga
}

\author{
Ika Buana Januarti*, Chintiana Nindya Putri \\ Prodi Farmasi, Fakultas Kedokteran, Universitas Islam Sultan Agung, Semarang, Indonesia \\ *Corresponding Author: \\ E-mail: bjanuarti@unissula.ac.id
}

$\begin{array}{cccc}\text { Received: } & \text { Revised: } & \text { Accepted: } & \text { Published: } \\ \text { 1 January 2021 } & \text { 15 April 2021 } & \text { 15 May 2021 } & 31 \text { May 2021 }\end{array}$

\begin{abstract}
Abstrak
Warga dawis Arbey RT 04 RW 04 Kelurahan Sampangan Semarang sebagian besar adalah ibu rumah tangga usia produktif. Lingkungan di daerah ini masih belum dimanfaatkan secara optimal sehingga mendorong pentingnya didirikan kelompok usaha yang memanfaatkan pekarangan rumah. untuk budidaya tanaman obat. Salah satu contoh TOGA yang mudah ditanam adalah daun bangun-bangun (Coleus amboinicus). Daun bangun-bangun berkhasiat sebagai pelancar ASI dengan dibuat menjadi jus siap minum. Pengembangan produk jus daun bangun-bangun perlu didukung oleh sarana prasarana, organisasi, SDM (Sumber Daya Manusia) dan pemasaran. Kegiatan pengabdian ini bertujuan untuk memberikan ketrampilan pada warga membudidayakan, mengolah produk daun bangun-bangun dan memasarkannya. Terdapat 2 metode yang digunakan yaitu penyuluhan dan praktik langsung. Materi penyuluhan adalah cara budidaya, pengolahan dan pemasaran jus daun bangun-bangun. Metode kedua adalah praktik budidaya dan pembuatan jus daun bangun-bangun. Hasil dari kegiatan pengabdian ini yaitu 15 orang peserta berhasil membudidayakan tanaman bangun-bangun.
\end{abstract}

Kata kunci: Bangun-bangun; budidaya; jus.

\begin{abstract}
Most of the residents of dawis Arbey RT $04 R W 04$ Kelurahan Sampangan Semarang are housewives of productive age. The environment in this area is still not optimally utilized, thus encouraging the importance of establishing business groups that utilize house yards. for the cultivation of medicinal plants. One example of TOGA that is easy to plant is the leaves of bangun-bangun (Coleus amboinicus). The leaves of the wakes have the effect of facilitating breast milk by being made into ready-to-drink juice. The development of leaf juice products needs to be supported by infrastructure, organization, human resources (human resources) and marketing. This service activity aims to provide skills to residents to cultivate, process leaf-building products and market them. There are 2 methods used, namely counseling and direct practice. The extension material is the method of cultivating, processing and marketing the juice from the leaves. The second method is the practice of cultivating and making leaf juice. The result of this service activity was that 15 participants succeeded in cultivating bangun-bangun.
\end{abstract}

Keywords: Bangun-bangun, cultivation, juice. 


\section{PENDAHULUAN}

ASI (Air Susu Ibu) merupakan kebutuhan yang sangat penting untuk bayi usia 0 sampai dengan 6 bulan. Target WHO pada tahun 2025 adalah pemberian ASI eksklusif usia 6 bulan pertama kelahiran meningkat minimal 50\% karena ASI eksklusif selama enam bulan pertama merupakan salah satu dari strategi global untuk meningkatkan pertumbuhan, perkembangan, kesehatan dan kelangsungan hidup bayi.

Di Indonesia, daun bangun-bangun banyak digunakan oleh masyarakat sebagai laktagoga (pelancar ASI), antiseptik, antibakteri, permasalahan sistem pernafasan (batuk, sinusitis, asma, influenza dan bronkhitis), mengatasi masalah pencernaan (dispepsia, diare, dan masuk angin), antiepilepsi, antiinflamasi, penyakit kulit, mengatasi gigitan serangga dan antioksidan (Arumugam et al, 2015; Damanik, R. , Wahlqvist, M.L., 2006). Masyarakat Sumatera Utara sudah terbiasa menggunakan bangun-bangun sebagai pelancar ASI. Penggunaan laktagogum dapat membantu ibu menyusui dalam meningkatkan sekresi dan produksi ASI yang rendah.

Ciri morfologi dari tanaman bangun-bangun adalah batang yang bulat dan sedikit berambut dan jarang berbunga (Husna et al., 2021). Tanaman ini merupakan tanaman yang mudah dibudidayakan. Adapun bagian tanaman yang digunakan sebagai pelancar ASI adalah daunnya. Daun bangun-bangun berbentuk bulat telur, tepi daun bergerigi, ujung daun tumpul, warna tulang daun hijau muda, terdapat bulu pada tulang daun serta memiliki aroma yang khas (Nasution et al., 2017). Menurut penelitian yang telah dilakukan oleh Hullatti dan Bhattacharjee (2011) daun bangun-bangun mengandung senyawa alkaloid, tanin, flavonoid, fenolik, triterpenoid, minyak atsiri karvakrol, timol, humulen, undekanal, terpinen, cymen, caryophyllene oxide, terpineol dan selinen. dan saponin yang jumlahnya paling banyak dibandingkan bagian tanaman bangunbangun lain seperti batang dan akar. Kandungan zat besi dan karoten dalam daun bangun-bangun juga memperkaya kandungan ASI sehingga meningkatkan jumlah zat besi, kalium, seng dan magnesium. Hal ini berefek kepada kondisi kesehatan ibu menyusui yang merasa bertenaga dan tidak mudah lelah.

Khasiat daun bangun-bangun sebagai pelancar ASI sudah beberapa kali diteliti. Pada studi yang dilakukan oleh Husna et al.(2021) di Kelurahan Seribu Dolok tahun 2020 bahwa dari 30 ibu yang habis melahirkan terdapat 22 orang yang mengkonsumsi daun bangun-bangun dan produksi ASI nya baik. Hasil analisis menggunakan uji Chi-Square diperoleh nilai sig $0,000<\alpha$ $=0,05, \mathrm{df}=2$ diperoleh $\mathrm{X} 2$ hitung $>\mathrm{X} 2$ tabel $(19,402>5,991)$, artinya terdapat hubungan antara konsumsi daun bangun - bangun terhadap produksi ASI responden. Penelitian lain berasal dari Kabupaten Simalungun tahun 2018 di mana 10 responden ibu nifas menunjukkan peningkatan produksi ASI setelah 7 hari pemberian daun bangun-bangun dibandingkan dengan jumlah ASI sebelum diberikan perlakuan. Jumlah daun bangun-bangun yang dapat dikonsumsi per hari sebagai pelancar ASI oleh masyarakat suku Batak adalah 120-150 gram per hari. Jumlah ini menjadi dasar untuk menentukan takaran dalam pembuatan jus daun bangun-bangun (Syarief et al., 2014).

Program pengabdian masyarakat ini bertujuan untuk mengenalkan budidaya tanaman bangun-bangun, cara pengolahan setelah pemanenan dan pemanfaatannya menjadi jus siap minum. Produk minuman ini dapat disajikan dengan rasa enak, cara pembuatan mudah dan kemasan yang menarik. Pengembangan produk jus daun bangun-bangun perlu didukung oleh sarana prasarana, organisasi, SDM dan pemasaran. Selama ini ibu-ibu belum mengetahui cara budidaya, pembuatan jus hingga cara pemasarannya. Oleh karena itu perlu ditingkatkan pengetahuan dan ketrampilannya agar menghasilkan jus daun bangun-bangun yang berkualitas, higienis dan enak.

Mitra dalam kegatan pelatihan dan pendampingan ini adalah Ibu Siti Romelah sebagai perwakilan Dawis Arbey. Ibu Siti sangat aktif dalam menggerakkan kegiatan kemasyarakatan dengan mencarikan pelatihan untuk meningkatkan taraf ekonomi warganya. Salah satunya melalui pelatihan budidaya tanaman obat di sekitar rumah beserta pengolahan produknya dengan 
bekerjasama melalui Perguruan Tinggi. Mitra kedua adalah Ibu Ambar selaku Ketua Dawis Arbey yang berperan untuk mengambil kebijakan Dawis dan mengkoordinir seluruh kegiatan. Ibu Ambar bertugas untuk memberikan informasi dari TP PKK Semarang dan memotivasi warganya jika ada pelatihan. Tempat pengabdian terletak di Kelurahan Sampangan Kecamatan Gajah Mungkur. Kecamatan ini mempunyai luas 9,07 hektar. Batas wilayah Kecamatan Gajah Mungkur Kelurahan Sampangan yaitu:

Sebelah Barat : Kelurahan Manyaran, Kecamatan Semarang Barat

Sebelah Selatan : Kelurahan Sukorejo, Kecamatan Gunungpati

Sebelah Utara : Kelurahan Bambankerep, Kecamatan Ngaliyan

Sebelah Timur : Kelurahan Bendan Ngisor, Kecamatan Gajahmungkur

Jumlah penduduk di Kecamatan Gajahmungkur pada tahun 2016 sebanyak 16.851 jiwa dengan pekerjaan PNS, TNI, Polri sebanyak 3242, angkutan 495, pedagang 2054, buruh bangunan 1576, buruh industri 2124, pengusaha 371, buruh tani 26, pensiunan 1122 dan lainnya sebanyak 5841 jiwa (Badan Pusat Statistik, 2016).

Dawis Arbey terdiri dari $28 \mathrm{KK}$ dengan 22 rumah tinggal. Letak rumah tinggal Dawis Arbey sangat strategis karena di sekitar daerah ini banyak berdiri kampus dan sekolah. Pekerjaan sebagian besar warga RT.04/RW 04 Kelurahan Sampangan adalah pedagang, warung makan dan ibu rumah tangga.

Potensi yang dimiliki oleh Dawis Arbey adalah lahan di sekitar rumah tinggal yang belum dimanfaatkan secara optimal dan sumber daya manusia (SDM). Lahan di sekitar rumah tinggal di Dawis Arbey apabila ditata secara baik dapat ditanami oleh tanaman obat seperti tanaman bangunbangun. Potensi yang kedua adalah SDM (Sumber Daya Manusia) usia produktif. Sebagian besar pekerjaan ibu-ibu di Dawis adalah ibu rumah tangga sehingga mempunyai waktu luang untuk budidaya tanaman obat dan mengolahnya menjadi produk.

Program ini sejalan dengan upaya pemerintah untuk mengajak masyarakat supaya gemar menanam TOGA (Tumbuhan Obat Keluarga) di lingkungannya agar tersedia tanaman untuk preventif maupun mengobati penyakit yang ringan. Tumbuhan Obat mengandung senyawa kimia yang mampu memberikan efek farmakologi baik sudah ataupun belum dibudidayakan yang dapat digunakan sebagai obat (Wardiah, 2015; Yatias, 2015). Tanaman obat tradisional yang banyak ditanam dan dimanfaatkan oleh masyarakat pada umumnya dikenal dengan sebutan TOGA. TOGA berdasarkan Kementerian Pertanian (2015) adalah tanaman berkhasiat yang ditanam di lahan pekarangan yang dikelola oleh keluarga, dimana ditanam dalam rangka memenuhi keperluan keluarga akan obat-obatan tradisional yang dapat dibuat sendiri. Fungsi TOGA sebagai sarana untuk mendekatkan tanaman obat kepada upaya-upaya kesehatan preventif (pencegahan), promotif (meningkatkan / menjaga kesehatan) dan kuratif (penyembuhan penyakit) Alasan masyarakat banyak memilih memanfaatkan tumbuhan obat sebagai pengobatan adalah karena relatif lebih aman dibandingkan obat konvensional, murah, mudah karena tumbuhan obat tersebut dapat dibudidayakan sendiri di rumah (Ningsih, 2016).

Potensi-potensi tersebut mendukung pentingnya didirikan usaha mandiri di Dawis Arbey untuk meningkatkan kesejahteraan. Adapun usaha yang dapat dilakukan dengan memanfaatkan lahan di sekitar rumah tinggal adalah budidaya tanaman obat bangun-bangun. Tanaman ini mudah ditumbuhkan dan tidak memerlukan lahan yang luas.

Berdasarkan analisis situasi maka dapat dirumuskan permasalahan prioritas mitra yang perlu dipecahkan bersama antara lain:

1. Lahan di sekitar rumah tingga yang belum dimanfaatkan secara optimal.

2. Terbatasnya pengetahuan ibu-ibu Dawis mengenai budidaya dan pemanfaatan tanaman obat khususnya bangun-bangun.

3. Kurangnya kesejahteraan ekonomi pada masyarakat di Dawis Arbey. 
Usulan prioritas permasalahan pada kegiatan pendampingan ini adalah

1. Masyarakat memerlukan ketrampilan untuk budidaya tanaman obat khususnya tanaman bangun-bangun karena tanaman ini mempunyai manfaat pengobatan yang beragam, mudah untuk ditumbuhkan dan tidak memerlukan lahan yang sangat luas sehingga cocok ditanam di daerah perkotaan.

2. Masyarakat memerlukan pengetahuan dan ketrampilan untuk mengolah dan mengemas produk dari tanaman bangun-bangun sehingga pemanfaatannya sebagai pelancar ASI menjadi lebih praktis dan takarannya juga terukur.

3. Masyarakat memerlukan pengetahuan pemasaran untuk memasarkan produk jus pelancar ASI menggunakan sosial media ataupun secara konvensional disertai pembinaan pengelolaan keuangan.

Target luaran kegiatan pengabdian masyarakat adalah sebagai berikut:

1. Meningkatnya pengetahuan dan kesadaran masyarakat untuk membudidayakan tanaman obat yang lain di sekitar rumah tempat tinggalnya

2. Meningkatnya penghijauan di lingkungan rumah tinggal Dawis Arbey

3. Meningkatnya kesejahteraan masyarakat melalui penjualan produk jus daun bangun-bangun

4. Meningkatnya kesehatan warga karena sudah diberikan pengetahuan mengenai cara budidaya tanaman sehingga warga dapat menanam TOGA (Tanaman Obat Keluarga) jenis lain

Pemecahan masalah mitra melalui kegiatan pelatihan tentang budidaya, pembuatan produk dan pemasaran hasil produk daun bangun-bangun berupa penyuluhan, transfer IPTEK pembudidayaan daun bangun-bangun pada lahan terbatas dengan teknik yang akan ditransferkan kepada mitra adalah teknik penanaman media kantong, pelatihan pengolahan/pembuatan produk daun bangun-bangun, pelatihan kewirausahaan dan metode pemasaran melalui skill kewirausahaan yang akan ditransferkan kepada mitra meliputi potensi wirausaha daun bangunbangun, teknik penjualan, teknik pengemasan dan strategi pemasaran.

\section{METODE}

Program pengabdian masyarakat dimulai dari wawancara dengan mitra mengenai permasalahan utama ibu-ibu warga Dawis Arbey. Permasalahan utama yang didapatkan yaitu lahan di sekitar rumah tinggal yang belum dimanfaatkan secara optimal dan kurangnya kesejahteraan warga. Tim kemudian meminta ijin kepada Ketua Dawis untuk memberikan pelatihan peningkatan ketrampilan ibu-ibu dalam budidaya dan pengolahan produk tanaman obat pelancar ASI bangunbangun. Tim membuat kesepakatan dengan mitra tentang jadwal pertemuan pada arisan Dawis karena keterbatasan pertemuan selama pandemi. Kesepakatan lain adalah ibu-ibu yang hadir hanya $50 \%$ dari peserta arisan karena sudah berusia lanjut

Metode pengabdian masyarakat adalah pemaparan materi dan praktik langsung kepada ibuibu Dawis Arbey sebagai peserta. Peserta akan mendapatkan materi tentang kandungan kimia, khasiat, cara budidaya dan pengolahan pasca panen daun bangun-bangun. Praktik langsung diberikan untuk 2 materi, yang pertama mengenai cara budidaya bangun-bangun di lahan terbatas menggunakan polybag atau metode tanam kantong memanfaatkan plastic, kantong bekas minyak dan sabun. Praktik yang kedua adalah pembuatan nutrasetikal jus daun bangun-bangun menggunakan peralatan rumah tangga blender, pisau dan talenan. Tindak lanjut dari kegiatan ini adalah pemantauan penanaman bibit ke masing-masing rumah penduduk untuk melihat keberhasilan budidaya bangun-bangun dalam jangka waktu satu bulan setelah pelaksanaan Data yang akan didapatkan adalah jumlah ibu-ibu yang sudah berhasil membudidayakan tanaman bangun-bangun. 


\section{HASIL DAN PEMBAHASAN}

Kegiatan pengabdian masyarakat dilaksanakan pada bulan November 2020 secara luring memanfaatkan pertemuan arisan Dawis Arbey di RT 04 Kelurahan Sampangan. Acara arisan didahului dengan pengumpulan iuran dilanjutkan pemberian informasi dari Ketua Dawis dan penyuluhan dari tim. Pembawa acara membuka penyuluhan dengan menyampaikan tujuan dan kegiatan pengabdian masyarakat. Kegiatan pengabdian masyarakat menggunakan metode penyuluhan dan praktik. Materi penyuluhan pertama adalah masyarakat diperkenalkan bentuk morfologi tanaman bangun-bangun, cara menanamnya dan bagaimana cara membudidayakannya. Masyarakat diberi keterampilan bagaimana cara membuat jus daun bangun-bangun yang lebih praktis digunakan. Kegiatan ini bertujuan agar masyarakat dapat memanfaatkan tanaman ini sebagai pelancar ASI dan dapat dijadikan peluang bisnis membantu perekonomian keluarga kandungan kimia, khasiat, cara budidaya dan pengolahan pasca panen daun bangun-bangun. Tim sudah menyiapkan bibit tanaman, media tanam dan polybag untuk pelatihan budidaya sehingga peserta dapat langsung praktik. Polybag, kemasan minyak literan atau kemasan sabun cuci piring dapat menjadi alternatif wadah tanaman yang ekonomis jika lahan yang dimiliki oleh masyarakat terbatas. Praktik budidaya dimulai dari memilih media tanam hingga pemindahan bibit ke pekarangan yang lebih luas. Media tanam yang digunakan dapat dibeli di toko tanaman terdiri atas tanah, pupuk dan sekam supaya mendukung pertumbuhan tanaman.

Cara budidaya bangun-bangun dimulai dari :

1. Persiapan media tanam dan pembibitan tanaman bangun-bangun :

a. Pembuatan sekam arang.

b. Penyiapan tanah untuk media tanam.

c. Penyiapan pupuk kandang.

d. Penyiraman tanah yang telah tercampur dengan pupuk agar tidak berdebu.

e. Tanah dan pupuk yang telah disiram dicampur dengan sekam arang.

f. Pencampuran semua komponen.

g. Media tanam yang telah jadi dimasukkan ke dalam polybag/wadah bekas kemasan minyak/karung.

2. Penanaman bibit bangun-bangun:

a. Bibit disiapkan dengan memotong batang indukan tanaman bangun-bangun yang sudah tua ditandai dengan batang berwarna merah.

b. Beberapa daun di sekitar pangkal batang dipotong, kemudian batang dipindahkan kedalam polybag atau kantong minyak yang telah diiisi media tanam.

c. Masing-masing polybag ditanami dengan satu bibit bangun-bangun.

d. Bibit yang telah ditanami di polybag, dijaga kelembapan medianya agar bibit tumbuh optimal

e. Satu minggu setelah pembibitan diletakkan di daerah teduh tidak terkena sinar matahari langsung.

f. Bibit yang sudah mulai tumbuh ditandai dengan jumlah daun yang semakin banyak dan terdapat pertambahan batang.

g. Bibit yang telah berumur 3 bulan dapat dipindah ke dalam pekarangan jika mempunyai lahan.

Materi penyuluhan yang kedua adalah pembuatan jus daun bangun-bangun. Daun yang sudah dipetik kemudian dicuci dengan air mengalir dan dikeringkan di bawah sinar matahari atau di almari pengering sambil dibolak balik agar merata kekeringannya. Daun yang sudah kering kemudian dihaluskan, diayak supaya ukuran partikelnya seragam. 3 sendok makan serbuk daun dicampur dengan $100 \mathrm{ml}$ susu/air, kental manis secukupnya, 1 sendok teh perasa makanan, 1-2 sendok makan gula/madu kemudian diblender sehingga menjadi jus. Jus yang sudah jadi dapat 
dikemas ke dalam pouch plastic kemudian ditempel stiker supaya menarik. Jus lebih baik jika disajikan dingin.

Materi yang ketiga yaitu pelatihan metode pemasaran. Teknik pemasaran yang baik harus mengikuti perkembangan jaman. Tren marketing pertama yang bisa dimanfaatkan antara lain penjualan melalui video marketing dan social media stories di Facebook, instagram, TikTok. Facebook marketplace dapat meningkatkan volume penjualan karena memudahkan pelaku usaha untuk memasarkan produk dan melakukan penjualan menggunakan smartphone (Susanto dkk, 2020). Keuntungan lain adanya marketplace karena tidak ada batas ruang, jarak dan waktu sehingga dapat melakukan aktivitas jual beli dengan murah, mudah, cepat dan mengefisienkan waktu (Yustiani dan Yunanto, 2017).

Kedua adalah User Generated Content (UGC) melalui konten yang diciptakan sendiri oleh konsumen atau follower brand. Brand menawarkan hadiah kepada konsumen, kemudian konsumen membuat -konten untuk memenuhi tantangan (challenge) yang diberikan oleh brand. Ketiga melalui pembuatan interactive content. Teknik ini bertujuan untuk menyajikan fitur-fitur yang juga mengundang interaksi dari para pembaca iklan dengan menyajikan infografis interaktif, survey, polling dan email interaktif. Teknik pengemasan produk juga disampaikan misalkan melalui bungkus yang unik disertai pesan berupa "quotes" supaya mendekatkan pelanggan. Hal ini juga termasuk strategi pemasaran yang dapat diterapkan.

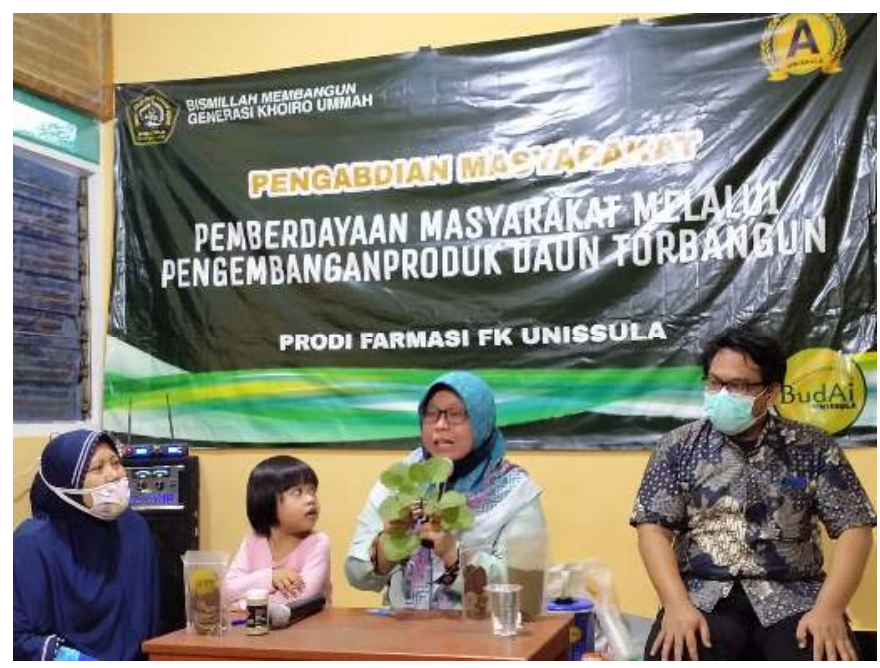

Gambar 1. Penyampaian materi budidaya Bangun-bangun oleh Tim.

17 orang peserta tampak antusias dan senang dalam mengikuti pelatihan karena mudah diaplikasikan di rumah untuk berwirausaha. Peserta menanggapi kegiatan dengan memberikan pertanyaan seputar kendala saat budidaya, pupuk yang digunakan dan pemindahan tanaman jika ingin menanam di lahan yang lebih luas. Tim juga akan membantu ibu-ibu untuk pengeringan daun bangun-bangun di laboratorium Farmasi Unissula dan pendampingan pemanenan. Pelatihan ditutup dengan pemberian bibit bangun-bangun kepada warga untuk ditanam di sekitar rumah tinggal. 


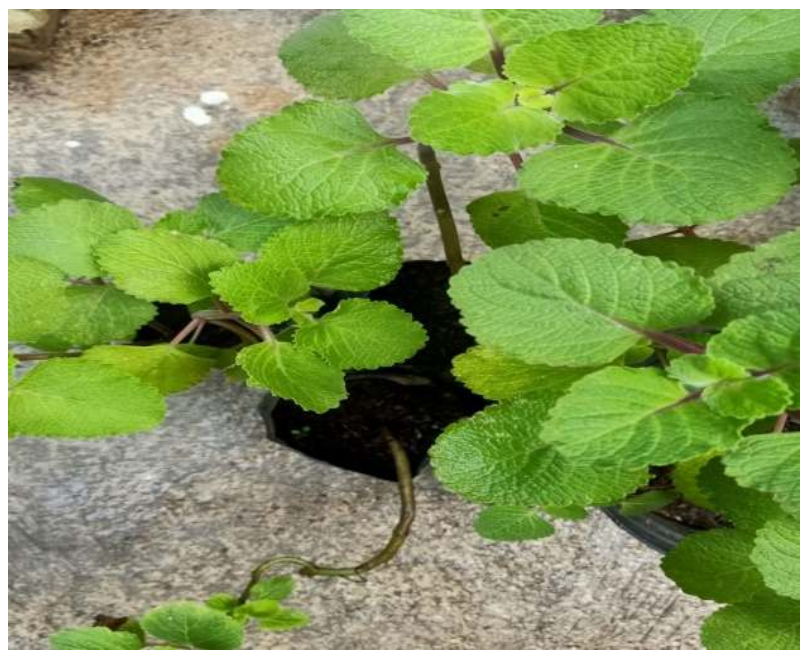

Gambar 2. Bibit bangun-bangun yang sudah ditanam warga di polybag.

Kegiatan pengabdian masyarakat mempunyai kendala jumlah peserta pelatihan yang terbatas dan waktu yang singkat karena dilaksanakan di masa pandemi. Hal ini tidak mengurangi semangat para peserta. Berdasarkan hasil pemantauan penanaman bibit pada saat satu bulan setelah pelaksanaan bahwa beberapa tanaman warga mati karena diletakkan di suhu yang terlalu panas sehingga tim membagikan bibit kembali dan memilihkan tempat yang sesuai untuk budidaya tanaman bangun-bangun. Jumlah peserta yang berhasil membudidayakan tanaman adalah 15 orang.

\section{KESIMPULAN}

Kesimpulan dalam kegiatan pengabdian ini adalah bahwa 15 orang peserta sudah berhasil membudidayakan tanaman bangun-bangun. Tim PKM ke depannya dapat menyediakan modul mengenai cara budidaya dan pengolahan produk daun bangun-bangun untuk diberikan masyarakat sehingga jika masyarakat memiliki kendala dapat membaca modul tersebut. Modul hasil pengabdian juga dapat didaftarkan menjadi buku ISBN dan hak cipta.

\section{UCAPAN TERIMA KASIH}

Ucapan terima kasih kami tujukan kepada Universitas Islam Sultan Agung melalui Lembaga Penelitian dan Pengabdian Masyarakat (LPPM) yang memberikan pendanaan melalui program Pengabdian Masyarakat internal, keluarga dan warga Dawis Arbey yang menyediakan tempat dan mengijinkan diadakannya pengabdian.

\section{DAFTAR PUSTAKA}

Arumugam, G., Swamy, M. K., \& Sinniah, U. R. (2016). Plectranthus amboinicus (Lour.) Spreng: botanical, phytochemical, pharmacological and nutritional significance. Molecules, 21(4), 369.

Badan Pusat Statistik. (2016). Kecamatan Gajahmungkur. Badan Pusat Statistik Semarang.

Damanik, R., Wahlqvist, M.L., W. N. (2006). Lactagogue effects of Torbangun, a Bataknese traditional cuisine. Asia Pac J Clin Nutr, 15(2), 267-274.

Hullatti, K. K., \& Bhattacharjee, P. (2011). Pharmacognostical evaluation of different parts of Coleus amboinicus lour., Lamiaceae. Pharmacognosy Journal, 3(24), 39-44. 
Husna, N., Panjaitan, D. B., Febriana, A., Ginting, Y., \& Purba, S. B. (2021). Hubungan daun bangun - bangun terhadap produksi ASI pada ibu nifas di Kelurahan Seribu Dolok. Jurnal Penelitian Kebidanan dan Kespro, 3(2), 33-39.

Nasution, N., Siregar, L., \& Bayu, E. (2017). Karakteristik Pertumbuhan Vegetatif dari Beberapa Aksesi Tanaman Bangun-Bangun (Plectranthus Amboinicus (Lour.) Spreng). Jurnal Agroekoteknologi Universitas Sumatera Utara, 5(1), 26-32. https://doi.org/10.32734/jaet.v5i1.14075

Ningsih, I. Y. (2016). Studi Etnofarmasi Penggunaan Tumbuhan Obat oleh suku Tengger di Kabupaten Lumajang dan Malang Jawa Timur. Jurnal Farmasi Indonesia.

Pertanian, K. (2015). Tanaman Obat "Warisan Tradisi Nusantara untuk Kesejahteraan Rakyat". Balai Penelitian Tanaman Rempah dan Obat.

Susanto, A., Sari, C.A., Moses, D.R.I, Rachmawanto, E.H., Mulyono, I.U, W. (2020). Implementasi Facebook Marketplace untuk Produk UMKM sebagai Upaya Peningkatan Pemasaran dan Penjualan Online. Abdimasku, 3(1), 42-51.

Syarief, H., Damanik, R. M., Sinaga, T., \& Doloksaribu, T. H. (2014). Pemanfaatan Daun Bangun-Bangun Dalam Pengembangan Produk Makanan Tambahan Fungsional Untuk Ibu Menyusui. Jurnal Ilmu Pertanian Indonesia, 19(1), 38-42.

Wardiah, et al. (2015). Etnobotani Medis Masyarakat Kemukiman Pulo Berueh Selatan Kecamatan Pulo Aceh Kabupaten Aceh Besar. EduBio Tropika, 3(1), 1-50.

Yatias, E. A. (2015). Etnobotani Tumbuhan Obat di Desa Neglasari Kecamatan Nyalindang Kabupaten Sukabumi Provinsi Jawa Barat. Fakultas Sains dan Teknologi UIN Syarif Hidayatullah.

Yustiani, R., \& Yunanto, R. (2017). Peran Marketplace Sebagai Alternatif Bisnis di Era Teknologi Informasi. Jurnal Ilmiah Komputer dan Informatika (KOMPUTA), 6(2). 